Clinical Research

\title{
Real-world patient characteristics associated with survival of 2 years or more after radium-223 treatment for metastatic castration-resistant prostate cancer (EPIX study)
}

Daniel J. George $\mathbb{I D}^{1 凶}$, Neeraj Agarwal (D) $^{2}$, Oliver Sartor ${ }^{3}{ }^{3}$, Cora N. Sternberg ${ }^{4}$, Bertrand Tombal ${ }^{5}$, Fred Saad (D) $^{6}$, Kurt Miller ${ }^{7}$, Niculae Constantinovici ${ }^{8}$, Helen Guo ${ }^{9}$, John Reeves ${ }^{9}$, XiaoLong Jiao ${ }^{9}$, Per Sandström ${ }^{9}$, Frank Verholen ${ }^{8}$, Celestia S. Higano $^{10}$ and Neal Shore ${ }^{11}$

(c) The Author(s) 2022

BACKGROUND: The real-world EPIX study was conducted to gather information about the characteristics of patients with metastatic castration-resistant prostate cancer (mCRPC) who survived $\geq 2$ years after treatment with the alpha-emitter radium-223.

METHODS: This retrospective study of electronic health records in the US Flatiron database (NCT04516161) included patients with mCRPC treated with radium-223 between January 2013 and June 2019. Median overall survival (OS) and prostate-specific antigen (PSA) response ( $\geq 50 \%$ reduction) from start of radium- 223 treatment were the primary and secondary endpoints, respectively. Patient characteristics were compared between those who survived $\geq 2$ years versus $<2$ years, including a subgroup who survived $<6$ months. RESULTS: In the 1180 patients identified, median OS was 12.9 months (95\% Cl: 12.1-13.7), and 13\% of patients with data at 6 months had a PSA response. The survival groups included 775 patients $(65.7 \%)$ who survived $<2$ years (including 264 (22.4\%) who survived $<6$ months) and 185 patients (15.7\%) who survived $\geq 2$ years; 220 patients (18.6\%) had incomplete follow-up data and were censored. On multivariate analysis, age $>75$ years, Eastern Cooperative Oncology Group performance status (ECOG PS) 2-4, visceral metastases, prior symptomatic skeletal events (SSEs), and prior chemotherapy were independently prognostic of reduced OS. For patients with survival $\geq 2$ years versus $<2$ years, median age was 71 versus 75 years, $4 \%$ versus $14 \%$ had ECOG PS $2-4,4 \%$ versus $10 \%$ had visceral metastases, $38 \%$ versus $44 \%$ had prior SSEs, and $16 \%$ versus $32 \%$ had prior chemotherapy.

CONCLUSIONS: In this study of men with MCRPC treated in real-world clinical practice, median OS was consistent with that seen in the phase 3 ALSYMPCA trial. Patients who survived $\geq 2$ years after the start of radium-223 were younger and had better ECOG PS, lower disease burden, and less use of prior chemotherapy than those who survived $<2$ years.

Prostate Cancer and Prostatic Diseases (2022) 25:306-313; https://doi.org/10.1038/s41391-021-00488-0

\section{INTRODUCTION}

Since the pivotal phase 3 trial of the alpha emitter radium223 (ALSYMPCA [1]), the mCRPC treatment landscape has evolved. Novel hormone agents were not available outside clinical trials during ALSYMPCA, but are widely available now, and chemotherapy is typically delayed to later lines [2]. In clinical practice, radium-223 is used in various lines of therapy, either as monotherapy or in combination with other agents, and is frequently administered following or layered onto sequential novel hormone agents [2]. Radium-223 may also be used before chemotherapy: in a subgroup analysis of participants enrolled in ALSYMPCA who had not previously received chemotherapy, treatment with radium-223 prolonged median overall survival (OS) by 4.6 months compared with placebo
(16.1 vs 11.5 months, respectively, HR $0.69,95 \% \mathrm{Cl}: 0.52-0.92$; $p=0.01)$ [3].

Choosing the appropriate patient and treatment sequence is important to optimize the survival benefit from radium-223 [4]. The present real-world study was conducted to help identify patients with $\mathrm{mCRPC}$ in whom radium-223 may offer the most benefit, by assessing the characteristics of patients who survived $\geq 2$ versus $<2$ years after the start of radium-223 therapy.

\section{PATIENTS AND METHODS}

\section{Study design and patients}

This retrospective cohort study used data from an electronic health record (EHR)-derived database. Flatiron (https://flatiron.com/real-world-evidence/)

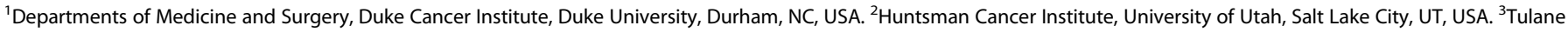

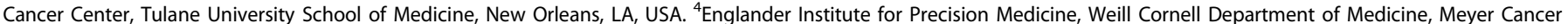

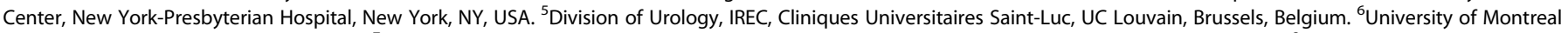

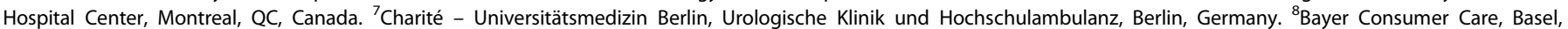

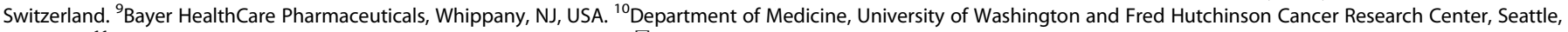
WA, USA. ${ }^{11}$ Carolina Urologic Research Center, Myrtle Beach, SC, USA. ${ }^{凶}$ email: daniel.george@duke.edu
} 


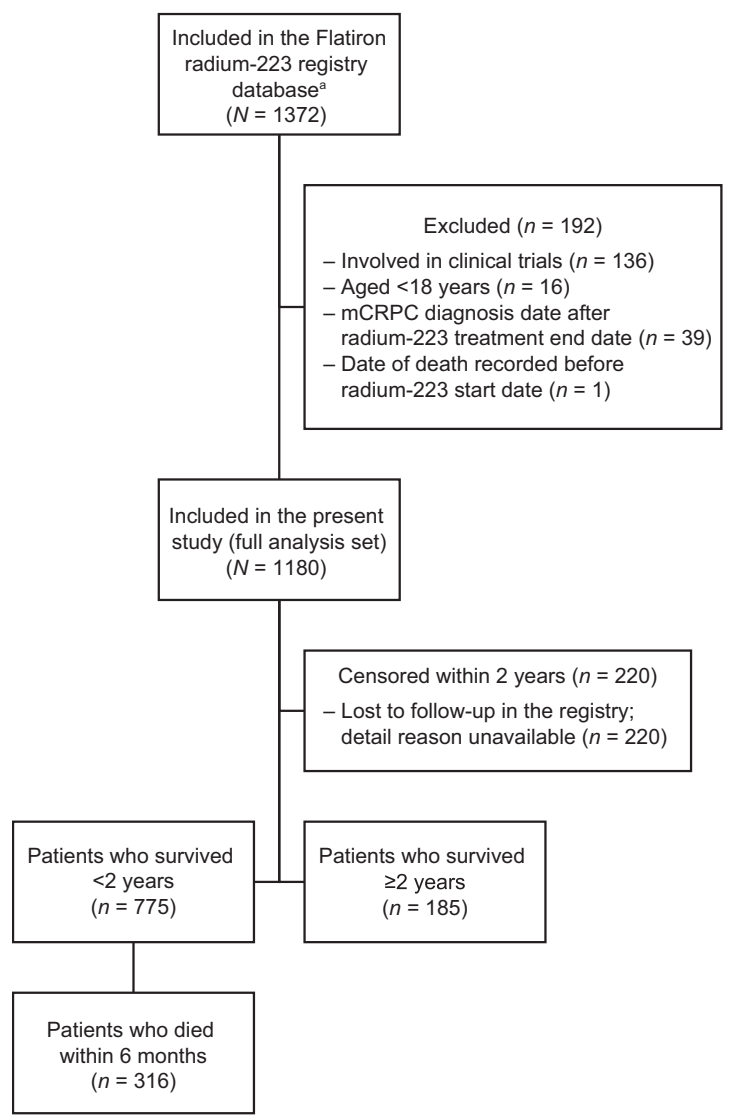

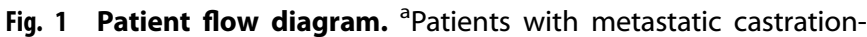
resistant prostate cancer treated with radium-223 any time between January 2013 and June 2019.

is a longitudinal, demographically and geographically varied database comprising EHR data from $>280$ community clinics and academic institutions, with data from almost 3 million patients with cancer in the USA available for analysis. The present cohort study included adult patients (aged $\geq 18$ years at diagnosis) with $\mathrm{mCRPC}$ treated with radium-223 as monotherapy or in combination with other life-prolonging anticancer therapies (e.g., abiraterone acetate and prednisone; enzalutamide; and/or taxanes) between January 2013 and June 2019. A cut-off date of December 2019 was applied for the follow-up data. Patients involved in clinical trials were excluded.

\section{Study endpoints and analyses}

The primary outcome measure was median OS from start of radium-223 therapy. Kaplan-Meier estimates of OS were calculated for the overall cohort, with multivariate Cox proportional hazards models used to identify significant predictors of OS. Patients alive at the time of database cut-off were censored at the last date known to be alive. SAS version 9.4 (SAS Institute Inc., Cary, NC, USA) was used for statistical analyses.

PSA response, defined as a $50 \%$ or greater reduction in baseline PSA level after initiation of radium-223, was the secondary endpoint, measured in patients with baseline PSA $\geq 10 \mu \mathrm{g} / \mathrm{L}$ and with $\geq 1$ PSA measurement between 15 days and 6 months after radium-223 start. Alkaline phosphatase (ALP) response, defined as a $\geq 30 \%$ reduction in ALP from baseline at any timepoint after initiation of radium-223 therapy, was also assessed in patients who had ALP levels measured at baseline and at least once $>15$ days after starting radium-223 therapy.

Baseline characteristics and treatments were reported descriptively for the overall cohort and for patients with survival $\geq 2$ years and $<2$ years (including a subgroup with survival $<6$ months). Categorical variables were measured as frequencies and percentages, whereas mean (standard deviation [SD]) or median (range) was used for continuous variables.

\section{Study ethics}

As this study was a retrospective review of EHR data, no Institutional Review Board review or patient informed consent was required.

\section{RESULTS}

\section{Patient characteristics}

The study included 1180 patients with mCRPC from the Flatiron database who received radium-223 between January 2013 and June 2019 (full analysis set; Fig. 1). The group with overall survival $<2$ years after radium-223 comprised 775 patients (including 264 patients with survival $<6$ months), and the group with survival $\geq 2$ years after radium-223 comprised 185 patients; 220 patients were censored within 2 years because of insufficient follow-up data and were excluded from the descriptive group analyses.

Baseline patient and disease characteristics for all patients and by survival duration are shown in Table 1 . For patients who survived $\geq 2$ years versus $<2$ years, median age was slightly lower (71 vs 74 years); median time from MCRPC diagnosis to the start of radium-223 therapy was shorter (7.1 vs 9.9 months); the proportion of patients with bone-only metastases was greater ( $86 \%$ vs $79 \%)$, and the incidence of prior symptomatic skeletal events (SSEs) was lower ( $38 \%$ vs $44 \%$ ). In addition, patients who survived $\geq 2$ years versus $<2$ years had lower median levels of ALP (78 vs $133 \mathrm{U} / \mathrm{L}$ ) and lactate dehydrogenase ( $\mathrm{LDH} ; 188.5$ vs $227.5 \mathrm{U} / \mathrm{L}$ ) at baseline, although only 226 patients had a documented baseline value for $\mathrm{LDH}$. Baseline median hemoglobin level in the group with survival $\geq 2$ years $(12.8$ $\mathrm{g} / \mathrm{dL})$ was close to the normal range $(\geq 13.0 \mathrm{~g} / \mathrm{dL}$ in men [5]) and greater than in the group with survival $<2$ years $(11.6 \mathrm{~g} / \mathrm{dL})$.

Differences in baseline characteristics were more pronounced between patients who survived $\geq 2$ years versus $<6$ months. Lower proportions of men who survived $\geq 2$ years versus $<6$ months had baseline Eastern Cooperative Oncology Group (ECOG) performance status $2-4$ (4\% vs $24 \%$ ), documented visceral metastases ( $4 \%$ vs $14 \%$ ), and prior history of SSEs ( $38 \%$ vs $48 \%$ ), and baseline median serum ALP (78 U/L vs $168 \mathrm{U} / \mathrm{L})$ and PSA levels $(17 \mu \mathrm{g} / \mathrm{L}$ vs $133 \mu \mathrm{g} / \mathrm{L}$ ) were lower (Table 1).

\section{Treatment exposure and sequencing}

Radium-223 treatment exposure is shown in Table 2. In patients who survived $\geq 2$ years versus $<2$ years, a higher proportion received radium-223 as a first-line treatment for $\mathrm{MCRPC}$ (monotherapy or combination; $47 \%$ vs $26 \%$ ), and fewer patients received prior chemotherapy ( $16 \%$ vs $32 \%)$, prior novel hormone agents (i.e., abiraterone acetate and prednisone, or enzalutamide: $32 \%$ vs $64 \%$ ), or prior bone health agents (e.g., denosumab or zoledronic acid; $45 \%$ vs $64 \%)$.

Among 738 patients who did not receive radium-223 as first-line therapy, most ( $92 \%$ overall) received prior novel hormone agents, while fewer than half $(46 \%)$ received prior chemotherapy in the mCRPC setting. In the 78 patients who survived $\geq 2$ years who did not receive radium-223 first line, $77 \%$ received prior novel hormone agents and 39\% received prior chemotherapy for MCRPC. In the 527 patients who survived $<2$ years who did not receive radium-223 first line, $94 \%$ received prior novel hormone agents and $47 \%$ received prior chemotherapy for MCRPC.

Most patients $(71 \%)$ who survived for $\geq 2$ years received radium223 as a first or second line of therapy; only $4 \%$ received radium-223 as a fourth or later line. In the group of patients who survived for $<2$ years, the proportion who received radium-223 in first or second line was lower $(58 \%)$, while $15 \%$ of them received it as a fourth or later line. In patients who survived $<6$ months, the proportions were $53 \%$ and $21 \%$, respectively. The proportion of patients who received radium-223 in combination with other life-prolonging therapies (most commonly novel hormone agents) was similar among patients who survived for $\geq 2$ years $(43 \%)$ or $<2$ years $(37 \%)$.

Almost all patients (84\%) who survived for $\geq 2$ years received 5 or 6 of the planned 6 injections of radium-223, compared with 
Table 1. Patient and disease characteristics of patients who received radium-223 in the real world.

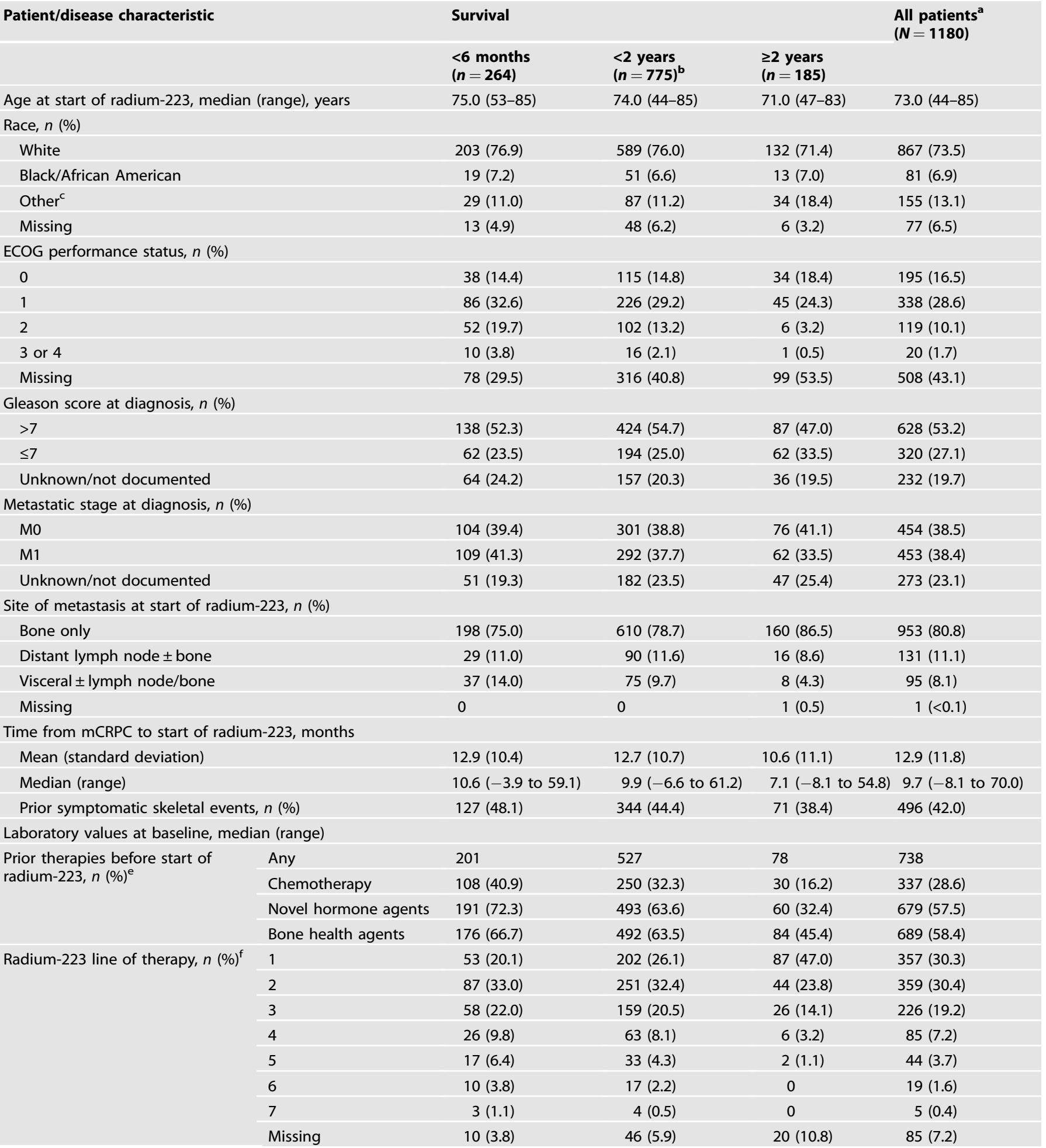

ECOG Eastern Cooperative Oncology Group, $M$ metastasis, $m C R P C$ metastatic castration-resistant prostate cancer.

${ }^{a}$ Full analysis set, including patients censored before 2 years.

${ }^{\mathrm{b}}$ Includes the 264 patients with survival $<6$ months.

"Other race includes patients who identified as Asian, Hispanic, Latino, or "Other".

${ }^{\mathrm{d}}$ PSA value was set to $30,000 \mu \mathrm{g} / \mathrm{L}$ if the original value was larger than $30,000 \mu \mathrm{g} / \mathrm{L}$.

e Patients could have received more than one treatment before radium- 223 and could have continued to receive a therapy started before radium-223 initiation during and after they received radium-223.

fIncludes use as monotherapy or in combination with life-prolonging therapies (e.g., abiraterone acetate and prednisone; enzalutamide; and/or taxanes) in the metastatic setting. 
Table 2. Real-world use of radium-223 in patients with metastatic castration-resistant prostate cancer.

\begin{tabular}{|c|c|c|c|c|}
\hline $\begin{array}{l}\text { Patients treated with radium-223, } \\
n(\%)\end{array}$ & $\begin{array}{l}\text { Survived }<6 \text { months } \\
(n=264)\end{array}$ & $\begin{array}{l}\text { Survived }<2 \text { years } \\
(n=775)^{a}\end{array}$ & $\begin{array}{l}\text { Survived } \geq 2 \text { years } \\
(n=185)\end{array}$ & $\begin{array}{l}\text { All patients } \\
(N=1180)\end{array}$ \\
\hline Monotherapy & $162(61.4)$ & $446(57.5)$ & $86(46.5)$ & $654(55.4)$ \\
\hline Combination therapy & $92(34.8)$ & $283(36.5)$ & $79(42.7)$ & 441 (37.4) \\
\hline $\begin{array}{l}\text {-Hormonal therapy }+ \\
\text { chemotherapy }\end{array}$ & $5(1.9)$ & $12(1.5)$ & $1(0.5)$ & $15(1.3)$ \\
\hline -Other & $1(0.4)$ & $1(0.1)$ & $1(0.5)$ & $3(0.3)$ \\
\hline Missing & $10(3.8)$ & $46(5.9)$ & $20(10.8)$ & $85(7.2)$ \\
\hline \multicolumn{5}{|l|}{ Injections received ${ }^{C}$} \\
\hline 6 & $5(1.9)$ & $264(34.1)$ & $143(77.3)$ & $543(46.0)$ \\
\hline
\end{tabular}

ancludes the 264 patients with survival $<6$ months.

${ }^{b}$ Full analysis set, including patients censored before 2 years.

${ }^{c}$ Radium-223 should be given as 6 injections at 4-week intervals; one patient censored within 2 years received 7 injections.

$45 \%$ of patients who survived for $<2$ years. Reasons for the reduced number of injections were not captured; however, it should be noted that $34 \%$ of patients ( 264 of 775 ) in the $<2$-year survival group survived for $<6$ months; therefore, many patients would not have had the opportunity to complete 5 or 6 months of treatment.

\section{Overall survival}

Median OS from the start of radium-223 was 12.9 months $(95 \% \mathrm{Cl}$ : 12.1-13.7) (Fig. 2). On univariate analysis, factors significantly associated with reduced OS were age $>75$ versus $<65$ years, baseline ECOG performance status 2-4 versus 0 , presence of visceral versus bone-only metastases, raised baseline levels of ALP, LDH, and PSA, prior SSEs, prior chemotherapy, and prior therapy with a bone health agent; whereas "other" race (including Asian, Hispanic, Latino, and "other", as self-identified by the patient) and higher baseline hemoglobin levels were significantly associated with improved OS (Supplementary Table S1). On multivariate analysis, age $>75$ years, ECOG performance status $2-4$ at baseline, presence of visceral metastases, prior SSEs, and prior chemotherapy were independently prognostic of reduced OS, whereas "other" race was independently prognostic of improved OS (Table 3).

\section{PSA and ALP responses}

Within 6 months after initiation of radium-223 therapy (either as monotherapy or in combination with another life-prolonging therapy), a reduction in PSA level of $\geq 50 \%$ from baseline was observed in $74(13 \%)$ of 566 patients with baseline PSA $\geq 10 \mu \mathrm{g} / \mathrm{L}$ and $\geq 1$ PSA measurement post-baseline.

Among patients with a baseline ALP measurement and at least one measurement $>15$ days after starting radium-223, an ALP response ( $\geq 30 \%$ ALP reduction from baseline) was achieved in 387 of 849 patients (46\%) overall, 68 of 107 patients (64\%) who survived $\geq 2$ years, 247 of 584 patients $(42 \%)$ who survived $<2$ years, and 57 of 220 patients (26\%) who survived $<6$ months.

\section{DISCUSSION}

In this analysis of real-world radium-223 use, the median OS was slightly shorter than that seen in the ALSYMPCA trial (12.9 vs 14.9 months [1]), which was conducted in an era before the availability of abiraterone and enzalutamide. In current clinical practice, several treatment options are available to patients, and our analysis shows that radium-223 is used in various treatment lines and in combination with other life-prolonging anticancer therapies in a high proportion of patients (37\% overall). The shorter median OS in comparison with ALSYMPCA suggests that radium-223 is being used in a wider population, including those with poorer prognostic features such as the presence of visceral metastases, which were an exclusion criterion in ALSYMPCA. According to its licensed indication, radium-223 should not be used in patients with visceral metastasis. In this retrospective review of patient health records, detailed insights into the treatment decisions for each patient with visceral metastases are not available, but we can assume that the treating physicians would have considered the expected benefit for individual patients. It cannot be excluded that patients with visceral metastases received combination treatment with other agents or may have had stable visceral metastases with symptomatic bone metastasis. Slightly more patients with survival $<2$ years received chemotherapy as concomitant therapy, compared with patients who survived $\geq 2$ years. The low PSA response rate (13\%) in this analysis reflects the mechanism of action of radium-223, which is bone targeted and has no direct impact on the androgen receptor signaling pathway. Of note, previous analyses have shown that neither PSA response nor PSA progression at week 12 is a prognostic marker of survival in men with CRPC and symptomatic bone metastases [6]. An ALP response (30\% reduction from baseline at any time after radium-223 initiation) was more common in patients with survival $\geq 2$ years versus $<2$ years.

We were interested in characterizing patients with longer versus shorter survival following radium-223 therapy, and we prespecified 2 years as the minimum for clinically relevant "long-term" survival. When we subsequently analyzed the OS data in quartiles, the cut-offs for the shortest and longest quartiles were $\sim 6$ months and 2 years, supporting our categories. Given the small group sizes, we did not undertake statistical comparisons of the survival groups. However, on a purely descriptive analysis, we saw better ECOG performance status, bone-only metastases, a slightly lower incidence of prior SSEs, less use of prior chemotherapy, lower baseline levels of ALP and LDH, and greater hemoglobin levels in patients with survival $\geq 2$ years versus survival $<2$ years. 


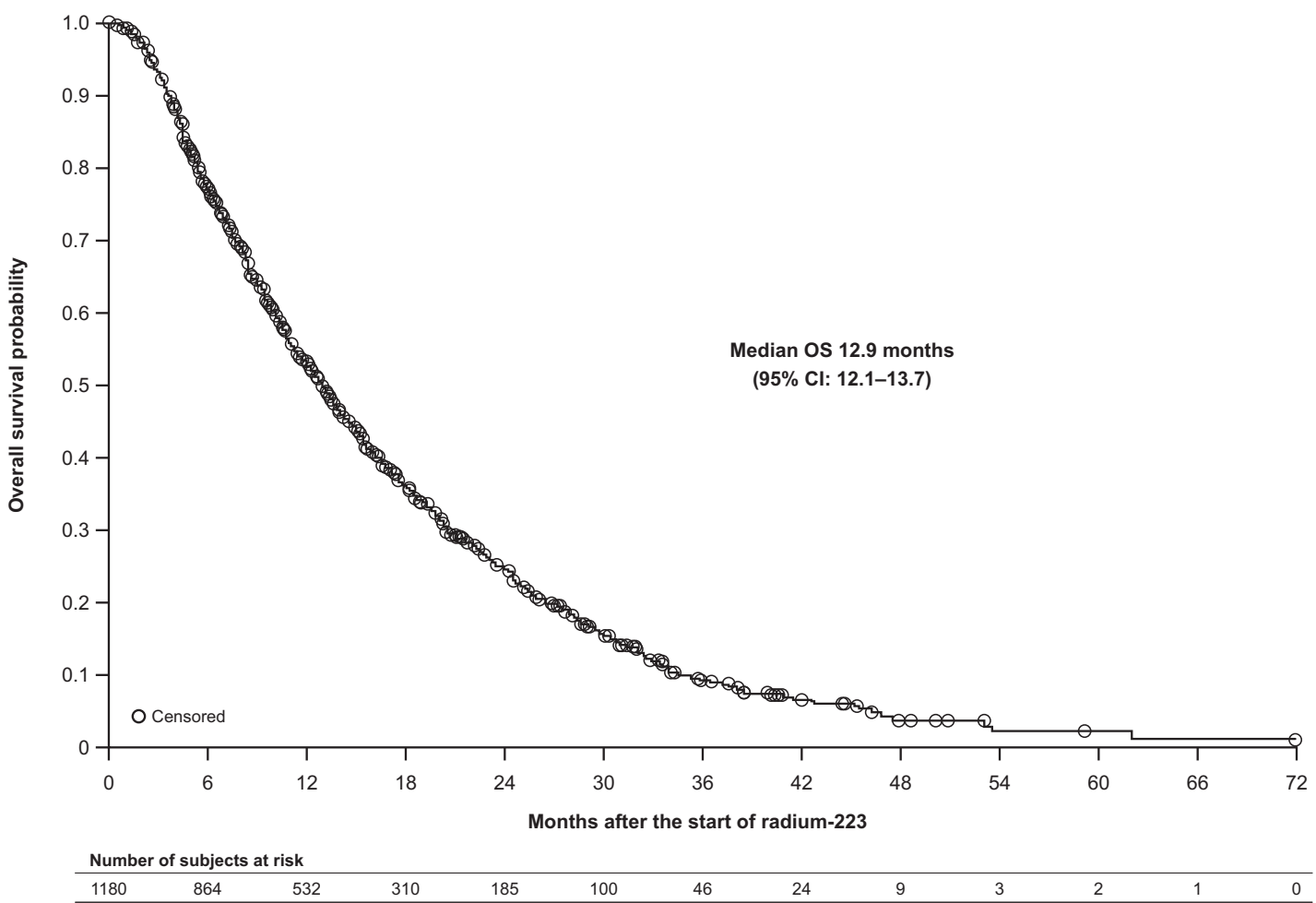

Fig. 2 Overall survival. Kaplan-Meier estimate; full-analysis set.

Table 3. Baseline patient and disease characteristics independently prognostic of overall survival in standard multivariate analysis (full-analysis set) ${ }^{a}$.

\begin{tabular}{|c|c|c|c|c|}
\hline Characteristic & Variable class & Hazard ratio & $95 \% \mathrm{Cl}$ & $\boldsymbol{p}$ value \\
\hline \multirow[t]{2}{*}{ Age at start of radium-223 (reference: $<65$ years) } & $65-75$ years & 1.08 & $0.90-1.31$ & 0.4183 \\
\hline & $>75$ years & 1.46 & $1.21-1.77$ & $<0.0001$ \\
\hline \multirow[t]{3}{*}{ Race (reference: white) } & Black or African American & 0.95 & $0.73-1.24$ & 0.7217 \\
\hline & Missing & 1.20 & $0.90-1.59$ & 0.2126 \\
\hline & Other $^{\mathrm{b}}$ & 0.68 & $0.55-0.84$ & 0.0003 \\
\hline \multirow[t]{2}{*}{ Baseline ECOG performance status (reference: 0) } & 1 & 1.15 & $0.93-1.41$ & 0.2033 \\
\hline & Missing & 1.05 & $0.86-1.28$ & 0.6428 \\
\hline \multirow[t]{2}{*}{ Site of metastasis (reference: bone only) ${ }^{c}$} & Distant lymph node \pm bone & 1.18 & $0.95-1.45$ & 0.1329 \\
\hline & Visceral \pm lymph node/bone & 1.61 & $1.27-2.03$ & $<0.0001$ \\
\hline Prior symptomatic skeletal event (reference: no) & Yes & 1.19 & $1.04-1.37$ & 0.0096 \\
\hline Prior chemotherapy (reference: no) & Yes & 1.57 & $1.35-1.84$ & $<0.0001$ \\
\hline
\end{tabular}

Cl confidence interval, ECOG Eastern Cooperative Oncology Group.

${ }^{a}$ The initial model included age at start of radium-223, race, practice type, Gleason score at diagnosis, region, histology, group stage, tumor (T) stage, node (N) stage, metastasis (M) stage, baseline ECOG performance status, site of metastasis, prior bone health agent, prior symptomatic skeletal event, and prior chemotherapy. Baseline laboratory variables were not included in the model selection process, because of the high proportion of missing values.

bOther race includes patients who identified as Asian, Hispanic, Latino, or "Other"

'One patient with missing site of metastasis was removed from the analysis.

Furthermore, proportionally more patients who survived $\geq 2$ years versus $<2$ years were treated with radium-223 as their first or second line of therapy (71\% vs 58\%) and received 5-6 injections of radium-223 (84\% vs $45 \%)$. Many of these characteristics are known favorable prognostic factors associated with longer survival in patients with $\mathrm{MCRPC}$ [7-10], whereas other unfavorable prognostic factors were not associated with worse outcomes in our analysis. Taken together, these findings seem to support the survival benefit of early treatment initiation in patients with good prognostic factors. These results also indicate that radium-223, as appropriate, could be considered as one of the early treatment options integrated into the management of patients with mCRPC, with no apparent adverse impact on long-term prognosis.

Other real-world studies have shown correlations between overall survival and completion of 5 or 6 radium-223 injections, use of radium-223 in the first or second line, or use before chemotherapy [11-18]. Patients able to complete the full course of radium-223 injections are likely to have fewer symptoms (including less pain), less disease burden, a good performance status, low baseline PSA and ALP levels, and high baseline hemoglobin levels $[11,19-23]$. Although these findings from realworld studies require confirmation in a prospectively designed 
clinical trial, they support our belief that initiation of radium-223 early in the MCRPC disease course is appropriate, while patients have a lower burden of disease and are still fit enough to receive the full treatment course. Such use of radium-223 could avoid the drawbacks of sequential use of novel hormone agents, which may have limited and short-lived benefit [24-30], while acknowledging physicians' and patients' preferences to delay chemotherapy to avoid toxicities that affect quality of life [2, 31-33]. Consideration of the overall place of radium-223 in treatment sequencing is now particularly important given the increasing number of therapies available, and the opportunity for patients to receive more lines of therapy and to start other systemic therapies at an earlier disease stage [34]. Indeed, with the growing use of other systemic treatments in the metastatic hormone-sensitive prostate cancer space, there could be a role for radium-223 at the time of development of castration resistance in patients whose disease is already resistant to novel hormonal agents and/or docetaxel chemotherapy.

Of specific importance to treatment sequencing considerations is that radium-223 is well tolerated, and chemotherapy can be administered after radium-223 without excess hematologic toxicity $[1,3,35-38]$. Whereas the benefit to be gained when radium-223 is used after chemotherapy appears to be limited, radium-223 can also be used before or after novel hormone agents [18, 39-42]. In the ERA 223 trial, an increased fracture incidence with radium-223 in combination with abiraterone versus abiraterone alone was reported; however, in the PEACE III trial, this risk was largely mitigated when bone health agents were added to the combination of radium-223 plus enzalutamide versus enzalutamide alone [43-45]. Ideally, radium-223 should be initiated in bone-dominant disease when initial therapy is no longer effective $[4,46]$, and important factors to contemplate when considering radium-223 treatment are progressive bone metastases, emerging or progressive symptoms, limited or stable lymph node disease, and the absence of visceral metastases $[1,4,12,47]$. Radium-223 is administered as 6 injections at 4-week intervals, and thus can be completed relatively quickly, allowing patients to move on to subsequent therapies to maximize OS. Nevertheless, absolute clarity on treatment sequencing remains elusive.

A weakness of this study is that it was a retrospective analysis and therefore has the potential for selection bias. In addition, missing data at baseline and other timepoints-a problem common to real-world analyses-resulted in censoring of a number of patients. Nevertheless, strengths of real-world data are that they more accurately represent the population of patients seen in clinical practice and further define long-term safety and efficacy in a more diverse population than is included in clinical trials. These data therefore complement the ALSYMPCA findings.

\section{CONCLUSIONS}

This retrospective study of patients with mCRPC confirms the prognostic role of lower disease burden and bone-only disease. In addition, we found that proportionally more patients who survived $\geq 2$ years versus $<2$ years were treated with radium-223 as first- or second-line treatment and were able to complete 5 or 6 cycles of radium-223. We therefore suggest that, for selected patients, starting radium-223 early in the MCRPC disease course, while they are still relatively fit and able to receive the full 6 injections, may be an appropriate treatment strategy to help improve clinical outcomes.

\section{DATA AVAILABILITY}

The data underlying this publication were provided by Flatiron under contract to Bayer. Requests for access to the data should be made to Flatiron (https://flatiron.com).

\section{REFERENCES}

1. Parker C, Nilsson S, Heinrich D, Helle SI, O'Sullivan JM, Fosså SD, et al. Alpha emitter radium-223 and survival in metastatic prostate cancer. N. Engl J Med. 2013;369:213-223.

2. George DJ, Sartor O, Miller K, Saad F, Tombal B, Kalinovský J, et al. Treatment patterns and outcomes in patients with metastatic castration-resistant prostate cancer in a real-world clinical practice setting in the United States. Clin Genitourin Cancer. 2020;18:284-94.

3. Hoskin P, Sartor O, O'Sullivan JM, Johannessen DC, Helle SI, Logue J, et al. Efficacy and safety of radium-223 dichloride in patients with castration-resistant prostate cancer and symptomatic bone metastases, with or without previous docetaxel use: a prespecified subgroup analysis from the randomised, double-blind, phase 3 ALSYMPCA trial. Lancet Oncol. 2014;15:1397-406.

4. O'Sullivan JM, Carles J, Cathomas R, Gomez-Iturriaga A, Heinrich D, Kramer G, et al. Radium-223 within the evolving treatment options for metastatic castration-resistant prostate cancer: Recommendations from a European Expert Working Group. Eur Urol Oncol. 2020;3:455-63.

5. World Health Organization, Vitamin and Mineral Nutrition Information System. Haemoglobin concentrations for the diagnosis of anaemia and assessment of severity. Available at: https://www.who.int/vmnis/indicators/haemoglobin.pdf. Accessed Nov 2021.

6. Sartor O, Coleman RE, Nilsson S, Heinrich D, Helle SI, O'Sullivan JM, et al. An exploratory analysis of alkaline phosphatase, lactate dehydrogenase, and prostate-specific antigen dynamics in the phase 3 ALSYMPCA trial with radium223. Ann Oncol. 2017;28:1090-7.

7. Halabi S, Lin CY, Kelly WK, Fizazi KS, Moul JW, Kaplan EB, et al. Updated prognostic model for predicting overall survival in first-line chemotherapy for patients with metastatic castration-resistant prostate cancer. J Clin Oncol. 2014;32:671-7.

8. Halabi S, Lin CY, Small EJ, Armstrong AJ, Kaplan EB, Petrylak D, et al. Prognostic model predicting metastatic castration-resistant prostate cancer survival in men treated with second-line chemotherapy. J Natl Cancer Inst. 2013;105:1729-37.

9. Armstrong AJ, Lin P, Higano CS, Sternberg CN, Sonpavde G, Tombal B, et al. Development and validation of a prognostic model for overall survival in chemotherapy-naïve men with metastatic castration-resistant prostate cancer. Ann Oncol. 2018;29:2200-7.

10. Al-Ezzi EM, Alqaisi HA, lafolla MAJ, Wang L, Sridhar SS, Sacher AG, et al. Clinicopathologic factors that influence prognosis and survival outcomes in men with metastatic castration-resistant prostate cancer treated with radium-223. Cancer Med. 2021;10:5775-82

11. Saad F, Gillessen S, Heinrich D, Keizman D, O'Sullivan JM, Nilsson S, et al. Disease characteristics and completion of treatment in patients with metastatic castration-resistant prostate cancer treated with radium-223 in an international early access program. Clin Genitourin Cancer. 2019;17:348-355.e345.

12. Alva A, Nordquist L, Daignault $S$, George $S$, Ramos J, Albany $C$, et al. Clinical correlates of benefit from radium-223 therapy in metastatic castration resistant prostate cancer. Prostate. 2017;77:479-88.

13. Cheng S, Arciero V, Goldberg H, Tajzler C, Manganaro A, Kozlowski N, et al. Population-based analysis of the use of radium-223 for bone-metastatic castration-resistant prostate cancer in Ontario, and of factors associated with treatment completion and outcome. Cancer Manag Res. 2019;11:9307-19.

14. Buscombe J, Gillett D, Bird N, Powell A, Heard S, Aloj L. Quantifying the survival benefit of completing all the six cycles of radium-223 therapy in patients with castrate-resistant prostate cancer with predominant bone metastases. World J Nucl Med. 2021;20:139-44.

15. Sartor O, Appukkuttan S, Weiss J, Tsao CK. Clinical outcomes, management, and treatment patterns in patients with metastatic castration-resistant prostate cancer treated with radium-223 in community compared to academic settings. Prostate. 2021;81:657-66.

16. Vidal M, Delgado A, Martinez C, Correa JJ, Durango IC. Overall survival prediction in metastatic castration-resistant prostate cancer treated with radium-223. Int Braz J Urol. 2020;46:599-611.

17. Kuppen MC, Westgeest HM, van der Doelen MJ, van den Eertwegh AJ, Coenen JL, Aben KK, et al. Real-world outcomes of radium-223 dichloride for metastatic castration resistant prostate cancer. Future Oncol. 2020;16:1371-84.

18. Jiang $X Y$, Atkinson S, Pearson R, Leaning D, Cumming S, Burns A, et al. Optimising radium 223 therapy for metastatic castration-resistant prostate cancer - 5-year real-world outcome: Focusing on treatment sequence and quality of life. Clin Oncol. 2020;32:e177-e187.

19. Heidenreich A, Gillessen S, Heinrich D, Keizman D, O'Sullivan JM, Carles J, et al. Radium-223 in asymptomatic patients with castration-resistant prostate cancer and bone metastases treated in an international early access program. BMC Cancer. 2019;19:12.

20. Lavelli V, Nappi AG, Caputo P, Asabella AN, Fanelli M, Sardaro A, et al. Impact of pre-treatment variables on the completion of (223) radium-dichloride therapy in mCRPC patients with bone metastases. Hell J Nucl Med. 2019;22:153-63. 
21. Maruzzo M, Basso U, Borsatti E, Evangelista L, Alongi F, Caffo O, et al. Results from a large, multicenter, retrospective analysis on radium223 use in metastatic castration-resistant prostate cancer (mCRPC) in the Triveneto Italian region. Clin Genitourin Cancer. 2019;17:e187-e194.

22. Sartor O, Vogelzang NJ, Sweeney C, Fernandez DC, Almeida F, lagaru A, et al. Radium223 safety, efficacy, and concurrent use with abiraterone or enzalutamide: First U.S. experience from an expanded access program. Oncologist. 2018;23:193-202.

23. McKay RR, Jacobus $S$, Fiorillo $M$, Ledet EM, Cotogna PM, Steinberger $A E$, et al. Radium-223 use in clinical practice and variables associated with completion of therapy. Clin Genitourin Cancer. 2017;15:e289-e298.

24. Nuhn P, De Bono JS, Fizazi K, Freedland SJ, Grilli M, Kantoff PW, et al. Update on systemic prostate cancer therapies: management of metastatic castrationresistant prostate cancer in the era of precision oncology. Eur Urol. 2019;75:88-99.

25. Khalaf DJ, Annala M, Taavitsainen S, Finch DL, Oja C, Vergidis J, et al. Optimal sequencing of enzalutamide and abiraterone acetate plus prednisone in metastatic castration-resistant prostate cancer: a multicentre, randomised, open-label, phase 2, crossover trial. Lancet Oncol. 2019;20:1730-9.

26. Mori K, Miura N, Mostafaei H, Quhal F, Sari Motlagh R, Pradere B, et al. Sequential therapy of abiraterone and enzalutamide in castration-resistant prostate cancer: a systematic review and meta-analysis. Prostate Cancer Prostatic Dis. 2020;23:539-48.

27. Smith MR, Saad F, Rathkopf DE, Mulders PFA, de Bono JS, Small EJ, et al. Clinical outcomes from androgen signaling-directed therapy after treatment with abiraterone acetate and prednisone in patients with metastatic castration-resistant prostate cancer: Post hoc analysis of COU-AA-302. Eur Urol. 2017;72:10-13.

28. Attard G, Borre M, Gurney H, Loriot $Y$, Andresen-Daniil C, Kalleda R, et al. Abiraterone alone or in combination with enzalutamide in metastatic castrationresistant prostate cancer with rising prostate-specific antigen during enzalutamide treatment. J Clin Oncol. 2018;36:2639-46.

29. de Wit R, de Bono J, Sternberg CN, Fizazi K, Tombal B, Wülfing C, et al. Cabazitaxel versus abiraterone or enzalutamide in metastatic prostate cancer. N. Engl J Med. 2019;381:2506-18.

30. Kuppen MCP, Westgeest HM, van den Eertwegh AJM, van Moorselaar RJA, van Oort IM, Coenen JLLM, et al. Real-world outcomes of sequential androgenreceptor targeting therapies with or without interposed life-prolonging drugs in metastatic castration-resistant prostate cancer: results from the Dutch CastrationResistant Prostate Cancer Registry. Eur Urol Oncol. 2019;4:618-27.

31. Al-Batran SE, Hozaeel W, Tauchert FK, Hofheinz RD, Hinke A, WindemuthKieselbach $C$, et al. The impact of docetaxel-related toxicities on health-related quality of life in patients with metastatic cancer (QoliTax). Ann Oncol. 2015;26:1244-8.

32. Parker C, Castro E, Fizazi K, Heidenreich A, Ost P, Procopio G, et al. Prostate cancer: ESMO Clinical Practice Guidelines for diagnosis, treatment and follow-up. Ann Oncol. 2020;31:1119-34.

33. Eliasson L, de Freitas HM, Dearden L, Calimlim B, Lloyd AJ. Patients' preferences for the treatment of metastatic castrate-resistant prostate cancer: A discrete choice experiment. Clin Ther. 2017;39:723-37.

34. Halwani AS, Rasmussen KM, Patil V, Li CC, Yong CM, Burningham Z, et al. Realworld practice patterns in veterans with metastatic castration-resistant prostate cancer. Urol Oncol. 2020;38:1.e1-1.e10.

35. Parker C, Heidenreich A, Nilsson S, Shore N. Current approaches to incorporation of radium-223 in clinical practice. Prostate Cancer Prostatic Dis. 2018;21:37-47.

36. Sartor O, Hoskin P, Coleman RE, Nilsson S, Vogelzang NJ, Petrenciuc O, et al. Chemotherapy following radium-223 dichloride treatment in ALSYMPCA. Prostate. 2016;76:905-16.

37. Dizdarevic S, Petersen PM, Essler M, Versari A, Bourre JC, la Fougère $C$, et al. Interim analysis of the REASSURE (Radium-223 alpha Emitter Agent in nonintervention Safety Study in $\mathrm{mCRPC}$ popUlation for long-teRm Evaluation) study: patient characteristics and safety according to prior use of chemotherapy in routine clinical practice. Eur J Nucl Med Mol Imaging. 2019;46:1102-10.

38. Higano CS, Harshman LC, Dizdarevic S, Logue J, Richardson T, George S, et al. Safety and overall survival (OS) in patients (pts) with metastatic castrationresistant prostate cancer (mCRPC) treated with radium-223 (Ra-223) plus subsequent taxane therapy. J Clin Oncol. 2020;38:5542.

39. Higano C, Tombal B, Miller K, Saad F, Sartor O, Tangirala K, et al. Clinical outcome with radium-223 (Ra-223) in patients (pts) previously treated with abiraterone (Abi) or enzalutamide (Enza): A retrospective study of real-world (RW) data from pts with metastatic castration-resistant prostate cancer (mCRPC). Ann Oncol. 2018;29:viii288-viii289.

40. Miller K, Heinrich D, O'Sullivan J, Carles J, Wirth M, Nilsson S, et al. Radium-223 (Ra-223) therapy after abiraterone (Abi): analysis of symptomatic skeletal events (SSEs) in an international early access program (iEAP) in patients (pts) with metastatic castration-resistant prostate cancer (mCRPC). Ann Oncol. 2018;29: viii287.
41. Sartor O, George D, Tombal B, Agarwal N, Higano CS, Sternberg CN, et al. Realworld outcomes of second novel hormonal therapy or radium-223 following first novel hormonal therapy for mCRPC. Future Oncol. 2022;18:35-45.

42. Badrising SK, Louhanepessy RD, van der Noort V, Coenen J, Hamberg P, Beeker A, et al. A prospective observational registry evaluating clinical outcomes of Radium-223 treatment in a nonstudy population. Int J Cancer. 2020;147:1143-51.

43. Smith M, Parker C, Saad F, Miller K, Tombal B, Ng QS, et al. Addition of radium-223 to abiraterone acetate and prednisone or prednisolone in patients with castrationresistant prostate cancer and bone metastases (ERA 223): a randomised, double-blind, placebo-controlled, phase 3 trial. Lancet Oncol. 2019;20:408-19.

44. Gillessen S, Choudhury A, Rodriguez-Vida A, Nole F, Gallardo Diaz E, Roumeguere $T A$, et al. Decreased fracture rate by mandating bone protecting agents in the EORTC 1333/PEACEIII trial combining Ra223 with enzalutamide versus enzalutamide alone: An updated safety analysis. J Clin Oncol. 2021;39:Abstract 5002.

45. Shore N, Higano CS, George DJ, Sternberg CN, Saad F, Tombal B, et al. Concurrent or layered treatment with radium-223 and enzalutamide or abiraterone/prednisone: real-world clinical outcomes in patients with metastatic castrationresistant prostate cancer. Prostate Cancer Prostatic Dis. 2020;23:680-8.

46. Nørgaard M, Jensen A, Jacobsen JB, Cetin K, Fryzek JP, Sørensen HT. Skeletal related events, bone metastasis and survival of prostate cancer: a population based cohort study in Denmark (1999 to 2007). J Urol. 2010;184:162-7.

47. Saad F, Keizman D, O'Sullivan JM, Carles J, Wirth M, Gillessen S, et al. Analysis of overall survival by number of radium-223 injections received in an international expanded access program (iEAP). J Clin Oncol. 2016;34:Abstract 5082.

\section{ACKNOWLEDGEMENTS}

Medical writing support for the preparation of this article was provided by David Murdoch, BSc (Hons), and Sara Black, ISMPP CMPP ${ }^{\mathrm{TM}}$, of OPEN Health Communications (London, UK), with financial support from Bayer HealthCare. Editorial assistance in the preparation of this manuscript was provided by Lila Adnane (Bayer).

\section{AUTHOR CONTRIBUTIONS}

Research idea and study design: All authors. Data acquisition: Not applicable. Data analysis/interpretation: Statistical analyses were done by HG and JR; all authors reviewed and interpreted the results. Report writing: All authors, with support from OPEN Health Communications (London, UK). All authors contributed equally to the manuscript, accept responsibility for the completeness, accuracy, and integrity of the data, and approved the submitted manuscript for publication.

\section{FUNDING}

This study was sponsored by Bayer HealthCare, Whippany, NJ, USA.

\section{COMPETING INTERESTS}

DJG reports grants and/or fees from Acerta Pharma, the American Association for Cancer Research, Astellas, AstraZeneca, Axess Oncology, Bayer, BMS, Calithera, Capio Biosciences, EMD Serono, Exelixis, Flatiron, Ipsen, UroGPO, Janssen, Leidos Biomedical Research, Merck Sharp \& Dohme, Michael J Hennessey Associates, Millennium Med Publishing, Modra Pharmaceuticals, Myovant Sciences, NCl, Nektar Therapeutics, Novartis, Pfizer, Physician Education Resource, Sanofi, UroToday, and Vizuri Health Sciences. NA serves as a consultant for Astellas, AstraZeneca, Aveo, Bayer, Bristol Myers Squibb, Calithera, Clovis, Eisai, Eli Lilly, EMD Serono, Exelixis, Foundation Medicine, Genentech, Janssen, Merck, MEI Pharma, Nektar, Novartis, Pfizer, Pharmacyclics, and Seattle Genetics. OS reports grants and/or fees from Advanced Accelerator Applications, Astellas, AstraZeneca, Bayer, Bellicum, Blue Earth Diagnostics, Inc., Bristol Myers Squibb, Celgene, Constellation, Dendreon, EMD Serono, Innocrin, Invitae, Johnson \& Johnson, Merck, Myovant, Pfizer, Sanofi, and SOTIO. CNS serves as a consultant for Pfizer, MSD, Merck, AstraZeneca, Astellas, Sanofi-Genzyme, Roche-Genentech, Incyte, Immunomedics (now Gilead), BMS, Janssen, Foundation Medicine, Medscape, and UroToday. BT reports grants and fees from Amgen, Astellas, Bayer, Ferring, Janssen, and Sanofi-Genzyme. FS reports fees from Astellas, AstraZeneca, Bayer, Janssen, Merck, Pfizer, and Sanofi. KM reports fees from Astellas, Bayer, BMS, Ferring, Janssen, MSD, Novartis, Pfizer, and Roche. NC, HG, JR, XJ, PS, and FV are employees of Bayer. CSH reports grants and/or fees from Aptevo, Asana Aragon Pharma, Astellas, AstraZeneca, Bayer, Blue Earth Diagnostics, Churchill Pharma, Clovis, Dendreon, eFFECTOR Therapeutics, Endocyte, Emergent BioSolutions, Ferring, Genentech, Hinova, Hoffman-La Roche, Janssen, Medivation, Myriad, Orion, and Pfizer. NS serves as a consultant/advisor for AbbVie, Bayer, Janssen Scientific Affairs, Dendreon, Tolmar, Ferring, Astellas, Amgen, Pfizer, AstraZeneca, BMS, Myovant Sciences, Merck, Sanofi-Genzyme, Invitae, Myriad, 
Phosphorous, Sema4, Foundation Medicine, Guardant; serves on speakers' bureau for Janssen, Bayer, Dendreon.

\section{ADDITIONAL INFORMATION}

Supplementary information The online version contains supplementary material available at https://doi.org/10.1038/s41391-021-00488-0.

Correspondence and requests for materials should be addressed to Daniel J. George.

Reprints and permission information is available at http://www.nature.com/ reprints.

Publisher's note Springer Nature remains neutral with regard to jurisdictional claims in published maps and institutional affiliations.
Open Access This article is licensed under a Creative Commons Attribution 4.0 International License, which permits use, sharing, adaptation, distribution and reproduction in any medium or format, as long as you give appropriate credit to the original author(s) and the source, provide a link to the Creative Commons license, and indicate if changes were made. The images or other third party material in this article are included in the article's Creative Commons license, unless indicated otherwise in a credit line to the material. If material is not included in the article's Creative Commons license and your intended use is not permitted by statutory regulation or exceeds the permitted use, you will need to obtain permission directly from the copyright holder. To view a copy of this license, visit http://creativecommons. org/licenses/by/4.0/.

(c) The Author(s) 2022 